\title{
Communication
}

\section{Disease-Related Knowledge in New Zealand Children with Inflammatory Bowel Disease (IBD) and Their Parents}

\author{
Laura Appleton $(\mathbb{1})$ and Andrew S. Day *,+(i)

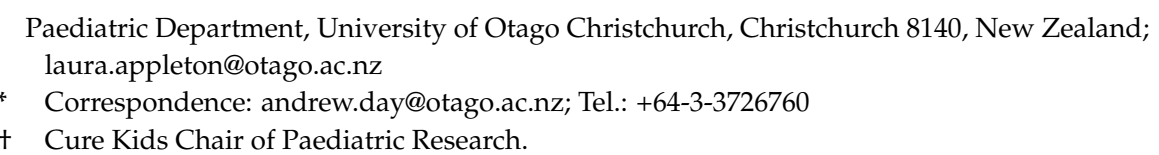

Abstract: Insufficient disease-related knowledge can be a barrier to the effective management of the unpredictable and lifelong course of inflammatory bowel disease (IBD). Patients with chronic illnesses have high non-adherence rates, with direct clinical consequences. While no single intervention strategy can improve the adherence of all patients, the success of attempts to improve patient adherence depends upon the realistic assessment of patients' knowledge and their understanding of the regimen. The aim of this study was to assess the disease-specific knowledge of the parents and patients with IBD in the South Island of New Zealand, and identify areas of poor knowledge. Families of children diagnosed with IBD were asked to complete the IBD Knowledge Inventory Device (IBDKID). Patients 10 years and older were asked to participate along with their parents. Of 110 families, 91 responded, with completed questionnaires received from 153 parents and 66 patients. Overall, parents scored significantly higher $(13.64 \pm 3.88)$ than their children $(10.03 \pm 4.07 ; p<0.001)$. Areas of poor knowledge included aspects of treatment (both conventional and alternative), along with long-term disease outcomes. This study has shown clear areas of concern in this population's diseasespecific knowledge of their disease. This should be addressed through targeted education for both the patient and the parents to improve not only their knowledge, but also their adherence and disease self-management.

Citation: Appleton, L.; Day, A.S. Disease-Related Knowledge in New Zealand Children with Inflammatory Bowel Disease (IBD) and Their Parents. Gastrointest. Disord. 2021, 3, 23-28. https://doi.org/10.3390/ gidisord 3010002

Received: 11 November 2020 Accepted: 9 January 2021 Published: 14 January 2021

Publisher's Note: MDPI stays neutral with regard to jurisdictional clai$\mathrm{ms}$ in published maps and institutional affiliations.

Copyright: $(\odot 2021$ by the authors. Licensee MDPI, Basel, Switzerland. This article is an open access article distributed under the terms and conditions of the Creative Commons Attribution (CC BY) license (https:// creativecommons.org/licenses/by/ $4.0 /)$.
Keywords: inflammatory bowel disease; Crohn's disease; ulcerative colitis; children; knowledge

\section{Introduction}

The conditions collectively known as inflammatory bowel disease (IBD), which include Crohn's disease (CD) and ulcerative colitis (UC), are characterized by lifelong relapsingremitting inflammation, and can present at any age through childhood [1]. Along with gastrointestinal (GI) symptoms, IBD in childhood has particular adverse effects upon weight and height, and may impair pubertal development [2]. It also impacts upon schooling, sports, quality of life, and is associated with depression and anxiety [3,4]. Further, after the induction of remission, most children diagnosed with these conditions require one or more ongoing therapies to maintain remission.

Following diagnosis with IBD, children and their families have much to learn about and understand. The acquisition of disease-specific knowledge is one important component during this time. Inadequate disease-specific knowledge may be a major barrier to effective management, and limit outcomes [5]. For instance, an improved adherence to medical therapies may be seen with increased disease-specific knowledge [6].

The IBD-Knowledge Inventory Device (IBD-KID) was developed as a simple tool to assess disease-specific knowledge in children aged ten years or older [7]. This 23-item tool has previously been used to assess IBD-related knowledge in Australian children and their parents [8,9]. In these studies, the IBD-KID tool was able to assess overall levels of knowledge and highlight knowledge gaps. 
The aim of this study was to assess the disease-related knowledge of patients and their parents in a group of children diagnosed with IBD in New Zealand.

\section{Results}

\subsection{Response Rate}

Of the 110 families approached, 91 (82.7\%) families responded, with the $219 \mathrm{com}$ pleted questionnaires received from 153 parents and 66 (81.45\%) patients. Five eligible patients (over 10 years) were excluded (not given questionnaire) due to concurrent mental health concerns (three), academic capability (one), or parent refusal (one). Of the 219 completed questionnaires, two parent questionnaires were invalid (and excluded) because one (or more) questions contained multiple answers.

\subsection{Respondents}

\subsubsection{Patient Population}

The total patient cohort was comprised of 91 children diagnosed with IBD (Table 1). Sixty-six of these children were aged 10 years of age and provided responses.

Table 1. Patient population characteristics.

\begin{tabular}{|c|c|c|}
\hline & $\begin{array}{c}\text { Patient Cohort } \\
\quad n=91\end{array}$ & $\begin{array}{c}\text { Child Respondents } \\
\qquad n=66\end{array}$ \\
\hline Male (\%) & $75(82.4)$ & $40(60.6)$ \\
\hline Age (years) ** & $13.1(1.5-18)$ & $13.7(10.1-18)$ \\
\hline Disease Duration (years) ** & $1.6(0-15)$ & $1.7(0-15)$ \\
\hline Patients Diagnosed < 12 months (\%) & $37(40.7)$ & $23(34.8)$ \\
\hline \multicolumn{3}{|l|}{ Disease Classification (\%) } \\
\hline CD & $78(85.7)$ & $57(86.3)$ \\
\hline UC & $11(12.1)$ & $7(10.6)$ \\
\hline IBDU & $2(2.2)$ & $2(3.0)$ \\
\hline
\end{tabular}

** Age and duration of diagnosis are expressed as medians (range). CD: Crohn's disease, UC: ulcerative colitis, IBDU: inflammatory bowel disease unclassified.

\subsubsection{Characteristics of Parent Respondents}

Of the 153 parental respondents, 66 (43.1\%) were male and 87 (56.9\%) female. Response from one parent only occurred $29(31.9 \%)$ times; if only one parent answered it was more likely to be the mother ( 25 replies from mothers only, versus 4 replies from fathers only). The average age of fathers was $46.07+/-7.45$ years and the average age of mothers was $43.25+/-5.05$ years.

\subsection{IBD-KID Scores}

The mean IBD-KID score for the children was 10.03 (4.07). Scores ranged from 3 to 20. Of the 1518 possible answers provided by the 66 children, "don't know" answers were provided on $456(30.0 \%)$ occasions.

There was no correlation between the age of the children and their IBD-KID score $(p=0.523)$. Nor was there a difference between scores according to gender $(p=0.436)$, type of disease classification $(p=0.278)$, or length of time since diagnosis $(p=0.736)$.

Parent's scores ranged between 3 and 22, with a mean score of $13.64 \pm 3.88$. "Don't know" answers were given 663 times (18.8\%) overall. Mother's mean scores were higher $(14.49+/-3.47)$ than father's scores $(12.57+/-4.14 ; p=0.002)$. There was no correlation between parental age and score $(p=0.564)$. Interestingly, parents of established diagnoses (>12 months) appeared to score less than their newly diagnosed counterparts, although this difference was not significant $(p=0.064)$. 


\subsection{Comparison between IBD-KID Scores of Children and Parents}

Overall, parents scored significantly higher $(13.64 \pm 3.88)$ than their children $(10.03 \pm 4.07 ; p<0.001)$. Areas of poor knowledge included aspects of treatment (both conventional and alternative), along with long-term disease outcomes. These areas of poor knowledge were similar in children and parents (Figure 1).

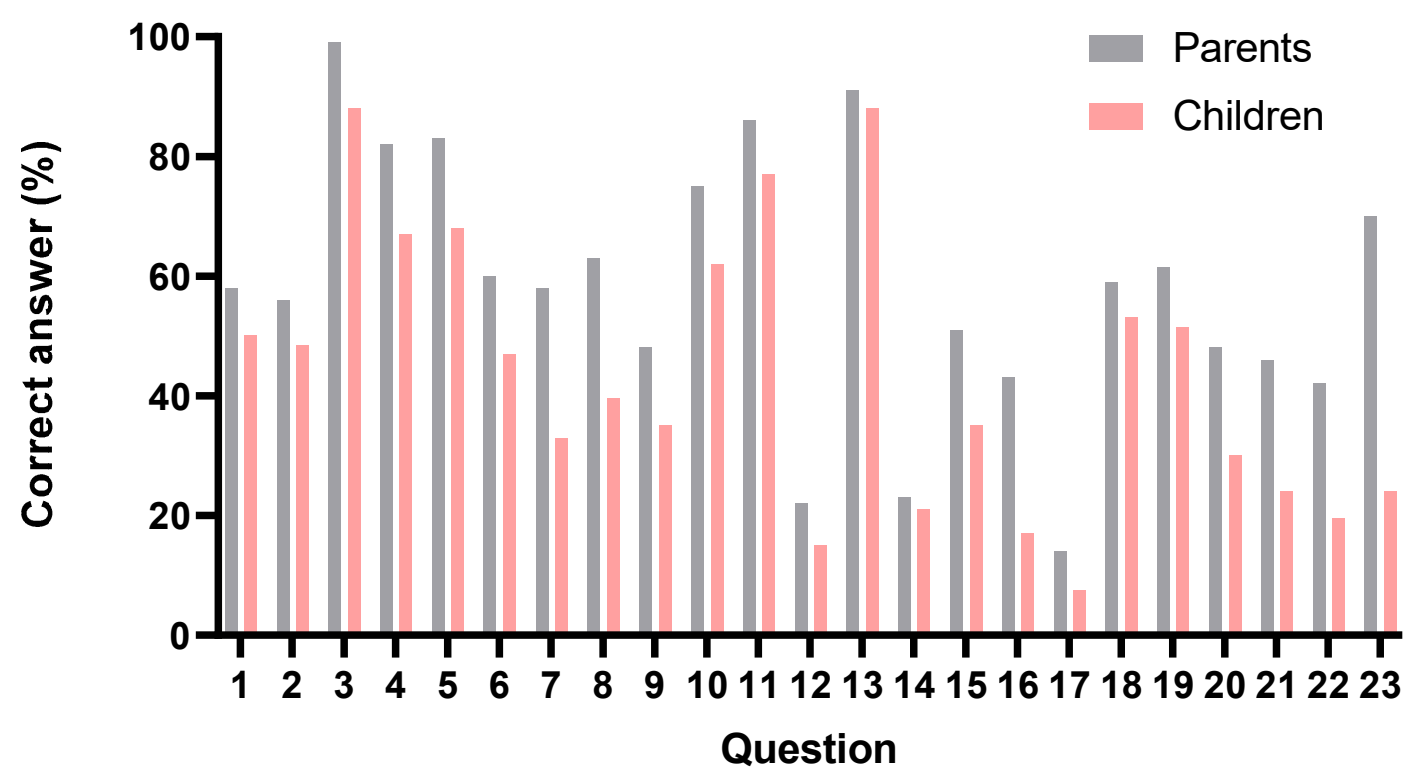

Figure 1. Comparison of parents' and children's correct answers according to IBD-KID question, showing areas of higher and lower knowledge.

\section{Discussion}

This study has demonstrated rates and patterns of disease-specific knowledge in a cohort of New Zealand children with IBD and their parents. Parents scored significantly higher than their children, as hypothesized. Of note, mothers scored significantly higher than fathers, which most likely reflects their primary caregiver role/situation [10]. While not significant, parents of children with more established diagnoses ( $>12$ months) scored slightly lower than their newly diagnosed counterparts; this could reflect newly diagnosed families having received disease education more recently.

Overall, these data demonstrate good overall disease-specific knowledge, but these findings also illustrate clear areas of concern in this population's knowledge of their disease. Areas of poor knowledge included aspects of treatment (both conventional and alternative), along with long-term disease outcomes. These areas of poor knowledge were similar in children and their parents. Enhanced knowledge about medications is known to help patients be more vigilant about possible adverse effects, and aids in the decision-making process about ceasing or changing treatments [11]. For example, the consequences of adding "natural" adjuvant medications without first discussing these changes with their physician. Further, Subasinghe et al. [12] noted that a lack of understanding about the possible complications of IBD could lead to the underestimation of the importance of colorectal cancer screening, with potentially significant consequences.

The IBD-KID tool was developed and validated in a Canadian setting as a tool to assess disease-specific knowledge in children and adolescents [7]. It was subsequently assessed and revalidated in Australia [8]; this localized version of the tool was utilized in the current study. The results from a further Australian study [9] are comparable to the current study. There are similar patterns of stronger knowledge with regards to the transmission of IBD and the role of stress in exacerbations of symptoms, with poorer knowledge in areas about herbal remedies and potential long-term consequences of uncontrolled IBD. Both the Australian parent and patient groups scored slightly higher than their New Zealand 
counterparts in this study $(14.19 \pm 4.02$; and $11.75 \pm 3.55$ respectively), although the reasons behind this difference remain unclear [9].

Prior to the development of the IBD-KID, the Crohn's and Colitis knowledge tool had been developed as a tool for adults [13]. More recently, IBD-KID has been translated into French, with some modifications, as the MICI-MINOTS [14].

Disease-specific knowledge has been linked with several important outcome variables in individuals with IBD. Colombara and colleagues [15] assessed knowledge in 91 adults with IBD using the CCKNOW, and demonstrated that increased knowledge was associated with a reduction in health care costs. CCKNOW was also used to assess knowledge in a group of 111 adults living in the USA, where it was demonstrated that greater diseasespecific knowledge was associated with the increased use of adaptive coping skills [16].

The importance of knowledge has also been examined in the context of preparation for the transition from pediatric to adult care. Gumidyala and colleagues [17] assessed knowledge in 75 adolescents and young adults, and related knowledge to factors such as older age, greater health care satisfaction and more frequent transition-related discussions with their health care provider. An evaluation of knowledge about their disease course in 78 Canadian adolescents preparing for transition identified gaps in knowledge, enabling focused educational initiatives [18].

Some adult reports have suggested an association between increased knowledge and increased worries or anxiety $[19,20]$. A more recent report evaluated knowledge and fear about colorectal cancer as an outcome in a group of French patients with IBD [21]. The patients with UC were more aware of this complication and more worried about this as an outcome. In contrast, no change in anxiety was seen after the introduction of an educational guideline in 240 English adults with UC [22], or after a group-based educational activity [23].

The current study was observational and did not incorporate any educational intervention. Several studies have demonstrated increased knowledge after focused educational activities [22,24]. More recently, two studies have documented improved knowledge about the reproductive implications of IBD following dedicated educational initiatives [25,26]. Further assessment of the impact of education upon disease-specific knowledge in children and adolescents is required.

The current study has provided data on a large population of children with IBD and their parents. This cross-sectional assessment of disease-specific knowledge did not provide any concurrent data on anxiety, medication adherence or other corelates of knowledge. Furthermore, it did not give any information about the longer-term maintenance of knowledge or the impact of this upon disease outcomes. A small number of the questionnaires were completed at home, and despite strict directions to the contrary some responses may be biased if educational aids or collaborations from others were utilized. However, the children included in the current study all have their IBD care provided by a single pediatric gastroenterology center, with consistent management and general disease-related teaching. While the findings are likely representative of children from the North Island of NZ, this cannot be confirmed.

In conclusion, this study has shown areas of concern in this population's knowledge of their disease. The IBD-KID can be used to identify such deficiencies that can then be addressed through targeted education for both the patient and the parents to improve not only knowledge, but also compliance and the self-management of disease.

\section{Materials and Methods}

\subsection{Subjects}

Families of children with new or established diagnoses of IBD presenting at outpatient clinics at Christchurch Hospital Pediatric Department, and IBD outreach clinics around the South Island, New Zealand, were approached and asked to complete the IBD-KID questionnaire. Patients aged between 10 and 18 years of age were asked to participate 
themselves, along with the parents/caregivers of all the children (including those children aged $<10$ years) approached.

Background patient characteristics (such as disease type, location and behavior, duration since diagnosis, sex, and age) were collected from for each child and their parents at enrolment.

The study was approved by the NZ National Ethics Committee (MEC/12/02/019, 3 July 2012).

\subsection{IBD-KID Questionnaire}

The IBD-KID questionnaire, which comprises 23 questions, was utilized as previously described [7-9]. This tool includes questions on general IBD knowledge as well as specific topics such as medications, complications and diet. Children were asked to complete the questionnaire by themselves, without parental input, in one sitting. Completed IBD-KID questionnaires were then returned to the investigators at a subsequent IBD Clinic or by mail. IBD-KID scores were expressed as mean (SD) correct answers unless otherwise stated.

\subsection{Statistics}

Statistical analysis was performed using IBM SPSS Statistics 25.0 (Chicago, Illinois, USA). Data are presented as means and standard deviations for each group unless otherwise stated. $T$-tests were used when comparing mean scores between parent and children groups. Spearman correlations were utilized between mean scores, and continuous variables and ANOVA for categorical variables of individual groups. Significance was classed as a value of less than or equal to 0.05 throughout.

Author Contributions: Conceptualization and study design A.S.D.; data collection and analysis L.A.; writing — original draft preparation, L.A.; writing—review and editing, A.S.D., L.A.; funding acquisition, A.S.D. All authors have read and agreed to the published version of the manuscript.

Funding: This work was funded by Cure Kids (Grant 3535).

Institutional Review Board Statement: The study was approved by the NZ National Ethics Committee (MEC/12/02/019, 03/07/2012).

Informed Consent Statement: Informed consent was obtained from all subjects involved in the study.

Data Availability Statement: The data that support the findings of this study are available from the corresponding author upon reasonable request.

Conflicts of Interest: The authors declare no conflict of interest.

\section{References}

1. Griffiths, A. Inflammatory Bowel Disease. In Paediatric Gastrointestinal Disease, 3rd ed.; Walker, W.A., Durie, P.R., Hamilton, J.R., Walker-Smith, J.A., Watkins, J.B., Eds.; BC Decker: Hamilton, ON, Canada, 2000; pp. 613-652.

2. Day, A.S.; Whitten, K.E.; de Jong, N.S.H. Nutrition and Nutritional Management of Crohns Disease in Children and Adolescents. Curr. Nutr. Food Sci. 2006, 2, 3-13. [CrossRef]

3. Bishop, J.; Lemberg, D.A.; Day, A. Managing inflammatory bowel disease in adolescent patients. Adolesc. Health Med. Ther. 2014, 5, 1-13. [CrossRef] [PubMed]

4. Day, A.S.; Whitten, K.E.; Sidler, M.; Lemberg, D.A. Systematic review: Nutritional therapy in paediatric Crohn's disease. Aliment. Pharmacol. Ther. 2008, 27, 293-307. [CrossRef] [PubMed]

5. Hou, J.; Turkeltaub, J.A.; Iii, T.R.M.; El-Serag, H.B. Assessment of disease specific knowledge and health-related quality of life among United States military veterans with inflammatory bowel disease. World J. Gastroenterol. 2015, 21, 6001-6007. [CrossRef]

6. Lim, J.K.; Lee, Y.J.; Park, J.H. Medication-Related Knowledge and Medication Adherence in Pediatric and Adolescent Patients with Inflammatory Bowel Disease. J. Korean Med. Sci. 2020, 35, e92. [CrossRef]

7. Haaland, D.; Day, A.S.; Otley, A. Development and validation of a pediatric IBD knowledge inventory device: The IBD-KID. J. Pediatr. Gastroenterol. Nutr. 2014, 58, 313-319. [CrossRef]

8. Day, A.S.; Lemberg, D.A.; Nichol, A.; Clarkson, C.; Otley, A.R. Generalisability of the inflammatory bowel disease knowledge inventory device to assess disease-related knowledge in Australian children. J. Paediatr. Child Health 2014, 50, 591-595. [CrossRef]

9. Day, A.S.; Mylvaganam, G.; Shalloo, N.; Clarkson, C.; Leach, S.T.; Lemberg, D.A. Assessment of disease-specific knowledge in Australian children with inflammatory bowel disease and their parents. J. Paediatr. Child Health 2017, 53, 778-781. [CrossRef] 
10. Cardinali, P.; Migliorini, L.; Rania, N. The Caregiving Experiences of Fathers and Mothers of Children With Rare Diseases in Italy: Challenges and Social Support Perceptions. Front. Psychol. 2019, 10, 1780. [CrossRef]

11. Lesnovska, K.P.; Börjeson, S.; Hjortswang, H.; Frisman, G.H. What do patients need to know? Living with inflammatory bowel disease. J. Clin. Nurs. 2014, 23, 1718-1725. [CrossRef]

12. Subasinghe, D.; Wijekoon, N.S.; Nawarathne, N.M.; Samarasekera, D.N. Disease-related knowledge in inflammatory bowel disease: Experience of a tertiary care centre in a developing country in South Asia. Singap. Med. J. 2010, 51, 484-489.

13. Eaden, J.A.; Abrams, K.; Mayberry, J.F. The Crohn's and Colitis Knowledge Score: A test for measuring patient knowledge in inflammatory bowel disease. Am. J. Gastroenterol. 1999, 94, 3560-3566. [CrossRef] [PubMed]

14. Cousin, C.; Bevilacqua, C.; Roman, C.; Roquelaure, B.; Loundou, A.; Baumstarck, K.; Fabre, A. MICI-MINOTS: Linguistic and metric validation of a pediatric questionnaire on knowledge about inflammatory bowel disease. Arch. Pediatrie 2020, 27, 110-116. [CrossRef] [PubMed]

15. Colombara, F.; Martinato, M.; Girardin, G.; Gregori, D. Higher levels of knowledge reduce health care costs in patients with inflammatory bowel disease. Inflamm. Bowel Dis. 2015, 21, 615-622. [CrossRef] [PubMed]

16. Moradkhani, A.; Kerwin, L.; Dudley-Brown, S.; Tabibian, J.H. Disease-specific knowledge, coping, and adherence in patients with inflammatory bowel disease. Dig. Dis. Sci. 2011, 56, 2972-2977. [CrossRef] [PubMed]

17. Gumidyala, A.P.; Plevinsky, J.M.; Poulopoulos, N.; Kahn, S.A.; Walkiewicz, D.; Greenley, R.N. What Teens Do Not Know Can Hurt Them: An Assessment of Disease Knowledge in Adolescents and Young Adults with IBD. Inflamm. Bowel Dis. 2017, 23, 89-96. [CrossRef]

18. Benchimol, E.I.; Walters, T.D.; Kaufman, M.; Frost, K.; Fiedler, K.; Chinea, Z.; Zachos, M. Assessment of knowledge in adolescents with inflammatory bowel disease using a novel transition tool. Inflamm. Bowel Dis. 2011, 17, 1131-1137. [CrossRef]

19. Martin, A.; Leone, L.; Castagliuolo, I.; Di Mario, F.; Naccarato, R. What do patients want to know about their inflammatory bowel disease? Ital. J. Gastroenterol. 1992, 24, 477-480.

20. Selinger, C.P.; Lal, S.; Eaden, J.; Jones, D.B.; Katelaris, P.; Chapman, G.; McDonald, C.; Leong, R.W.; McLaughlin, J. Better disease specific patient knowledge is associated with greater anxiety in inflammatory bowel disease. J. Crohn's Colitis 2013, 7, e214-e218. [CrossRef]

21. Lopez, A.; Collet-Fenetrier, B.; And, A.B.; Peyrin-Biroulet, L. Patients' knowledge and fear of colorectal cancer risk in inflammatory bowel disease. J. Dig. Dis. 2016, 17, 383-391. [CrossRef] [PubMed]

22. Kennedy, A.; Robinson, A.; Hann, M.; Thompson, D.; Wilkin, D.; North-West Region Gastrointestinal Research Group. A clusterrandomised controlled trial of a patient-centred guidebook for patients with ulcerative colitis: Effect on knowledge, anxiety and quality of life. Health Soc. Care Community 2003, 11, 64-72. [CrossRef] [PubMed]

23. Larsson, K.; Sundberg, M.H.; Karlbom, U.; Nordin, K.; Anderberg, U.M.; Loof, L. A group-based patient education programme for high-anxiety patients with Crohn disease or ulcerative colitis. Scand. J. Gastroenterol. 2003, 38, 763-769. [CrossRef] [PubMed]

24. Waters, B.M.; Jensen, L.; Fedorak, R.N. Effects of formal education for patients with inflammatory bowel disease: A randomized controlled trial. Can. J. Gastroenterol. 2005, 19, 235-244. [CrossRef] [PubMed]

25. Mountifield, R.; Andrews, J.M.; Bampton, P.A. It IS worth the effort: Patient knowledge of reproductive aspects of inflammatory bowel disease improves dramatically after a single group education session. J. Crohn's Colitis 2014, 8, 796-801. [CrossRef] [PubMed]

26. Wierstra, K.; Sutton, R.T.; Bal, J.; Ismond, K.; Dieleman, L.; Halloran, B.; Kroeker, K.; Fedorak, R.N.; Berga, K.-A.; Huang, V.W.-M. Innovative Online Educational Portal Improves Disease-Specific Reproductive Knowledge Among Patients With Inflammatory Bowel Disease. Inflamm. Bowel Dis. 2018, 24, 2483-2493. [CrossRef] [PubMed] 